\title{
Bone marrow-derived mesenchymal stem cells co-expressing interleukin-18 and interferon- $\beta$ exhibit potent antitumor effect against intracranial glioma in rats
}

\author{
GANG XU $^{1}$, YANWU GUO $^{2}$, ZHIYUAN SENG $^{1}$, GANG CUI $^{1}$ and JIANQIANG QU ${ }^{1}$ \\ ${ }^{1}$ Department of Neurosurgery, The Second Affiliated Hospital, School of Medicine, Xi'an Jiaotong University, Xi'an, \\ Shaanxi 710004; ${ }^{2}$ Department of Neurosurgery, The Affiliated Zhujiang Hospital, \\ South Medical University, Guangzhou 510282, P.R. China
}

Received June 5, 2015; Accepted July 7, 2015

DOI: 10.3892/or.2015.4174

\begin{abstract}
Bone marrow-derived mesenchymal stem cells (BMSCs) are promising gene vehicles for cancer gene therapy. In our previous study, we reported that BMSCs expressing interleukin (IL)-18 effectively inhibit the growth of glioma in rats. In the present study, we further detected the effect of BMSCs co-expressing IL-18 and interferon (IFN)- $\beta$, both of which are immunostimulatory cytokines. BMSCs were genetically engineered to express IL-18 and IFN- $\beta$ by transfection of recombinant lentivirus-mediated gene transfer. Results showed that BMSCs co-expressing the two cytokines displayed more significant inhibition effect on glioma cell growth in vitro when compared with BMSCs solely expressing IL-18 or IFN- $\beta$. Treatment of BMSCs co-expressing IL-18 and IFN- $\beta$ significantly prolonged the survival and inhibited tumor growth in a rat intracranial glioma model. Furthermore, these genetically engineered BMSCs remarkably promoted cell apoptosis, antitumor cytokine production and $\mathrm{CD}^{+}{ }^{+}$and $\mathrm{CD} 8^{+}$ T-cell infiltration in intracranial glioma tissues than BMSCs solely expressing IL-18 or IFN- $\beta$. Results of the present study suggested that IL-18 and IFN- $\beta$ had a synergistic effect on glioma inhibition. Moreover, results provided evidence that delivery of IL-18 and IFN- $\beta$ by BMSCs may be an excellent and promising approach to develop an effective treatment protocol for glioma therapy.
\end{abstract}

Correspondence to: Professor Gang Cui, Department of Neurosurgery, The Second Affiliated Hospital, School of Medicine, Xi'an Jiaotong University, 157 Xiwu Road, Xi'an, Shaanxi 710004, P.R. China

E-mail: cuigangsx@163.com

Abbreviations: BMSCs, bone marrow-derived mesenchymal stem cells; IL-18, interleukin-18; IFN- $\beta$, interferon- $\beta$

Key words: bone marrow-derived mesenchymal stem cells, glioma, interleukin-18, interferon- $\beta$

\section{Introduction}

Glioma, which is refractory to tumor therapies with high mortality and morbidity worldwide, is the most frequent intracranial tumor in humans $(1,2)$. Despite the improvement in treatment technology, the disease still has a poor prognosis and survival rate (3). Thereby, developing effective treatment methods is necessary. The lack of sufficient vehicles that specifically target glioma in the brain limits the development of effective therapies. In recent years, bone marrow-derived mesenchymal stem cells (BMSCs) were found to possess selective tumor-tropic properties, which can migrate throughout the experimental brain tumors (4). BMSCs were proposed as a novel cellular vehicles for local delivery of drugs or biological agents to gliomas due to their specific glioma tropism $(5,6)$. Therefore, BMSCs are promising gene vehicles for the treatment of gliomas.

The brain is an immune-privileged site that lacks lymphatic drainage due to the blood-brain barrier, which accelerates the development and progression of gliomas. Immunotherapy for the treatment of glioma has been reported (7). Interleukin (IL)-18 with a molecular weight of $18.3 \mathrm{kDa}$ is a member of IL family that specifically induces Th1 cytokine production, particularly interferon (IFN) $-\gamma$ from T cells and natural killer cells $(8,9)$. IL-18 activates cytotoxic T activity, augment $\mathrm{T}$ cell proliferation, enhance natural killer cytolytic activity and promote antigen presentation (10-12). Furthermore, IL-18 induces the production of IL-2, which has significant antitumor activity against experimental and clinical model of glioma $(13,14)$. Thereby, IL-18 has been proposed as potential immunomodulator for the treatment of malignant gliomas. IFNs containing IFN- $\alpha$, IFN- $\beta$ and IFN- $\gamma$ are a family of natural glycoproteins that activate immune cells, including macrophages, $\mathrm{T}$ cells and natural killer cells augmenting antitumor immunity and inhibiting oncogene expression and tumor angiogenesis (15-17). Of these IFNs, IFN- $\beta$ has been widely studied in the treatment of tumors. This glycoprotein displays potent antiproliferative activity against melanoma cells (18). IFN- $\beta$ also has a direct cytotoxic effect on glioma cells, and the intratumoral IFN- $\beta$ delivery significantly enhances the cytotoxic $\mathrm{T}$ and natural killer activity without any side-effect $(19,20)$. 
In summary, BMSCs possess specific glioma-tropic properties, which are ideal vehicles for gene therapy of gliomas. Our previous study demonstrated that IL-18-expressing BMSCs effectively inhibits intracranial glioma in rats in vivo (21). Considering the vital function of IFN- $\beta$ in inhibiting tumor growth, we speculated that the co-expression of IL-18 and IFN- $\beta$ displays more potent and effective antitumor effect against glioma. To test this hypothesis, we constructed a recombinant lentivirus co-expressing IL-18 and IFN- $\beta$, which was then introduced into BMSCs to engineer the BMSCs genetically to express both IL-18 and IFN- $\beta$. In the present study, we explored the effect of these engineered BMSCs in glioma treatment in vitro and in vivo in a rat intracranial glioma model.

\section{Materials and methods}

Experimental animals. Adult male Fisher 344 rats (9-11 weeks old, weighing 180-220 g) were purchased from Gongdong Medical Laboratory Animal Center (Guangzhou, China) and housed in the animal care facility under standard protocols. All animal procedures were conducted according to the institutional and the national guidelines approved by the Institutional Animal Care and Use Committee of Xi'an Jiaotong University.

Cell cultures. Rat9L glioma cells were obtained from American Type Culture Collection (ATCC; Manassas, VA, USA) and grown in Dulbecco's modified Eagle's medium (DMEM; Invitrogen, Carlsbad, CA, USA) supplemented with $10 \%$ fetal bovine serum (FBS; Invitrogen), $2 \mathrm{mM}$ L-glutamine, and $1 \%$ streptomycin and penicillin. 293FT cells (Invitrogen) were maintained in DMEM containing 10\% fetal calf serum and $1 \%$ streptomycin and penicillin. Primary rat BMSCs were isolated and cultured as described in our previous study (21). Fisher 344 rats were sacrificed via intraperitoneal injection of $10 \%$ chloral hydrate $(0.4 \mathrm{ml} / 100 \mathrm{~g})$. The femurs and tibias were isolated, and the medullary cavity was flushed with $5 \mathrm{ml}$ of DMEM, followed by density gradient centrifugation (Ficoll-Paque; BD Biosciences, Lincoln Park, NJ, USA) at 2,000 rpm for $15 \mathrm{~min}$. The mononuclear cells were then harvested and resuspended in low glucose DMEM supplemented with $15 \%$ FBS, $2 \mathrm{mM}$ L-glutamine and $1 \%$ streptomycin and penicillin. All these cells were cultured in a humidified incubator containing $5 \%$ $\mathrm{CO}_{2}$ at $37^{\circ} \mathrm{C}$.

Recombinant lentivirus construction and infection. The full length cDNAs of IL-18 and IFN- $\beta$ were amplified using pCR3.1-IL-18 (New England Biolabs, Beverly, MA, USA) and Ad-CMV-IFN- $\beta$ (provided by the Department of Microbiology, The Second Military Medical University, Shanghai, China), respectively. These cDNA fragments were subcloned into the lentiviral vector pLenti6/V5-DEST to construct the recombinant vectors pLenti6/V5-DEST-IL-18, pLenti6/V5-DEST-IFN- $\beta$ or pLenti6/V5-DEST-IL-18-IFN- $\beta$. These vectors were packaged using ViraPower ${ }^{\mathrm{TM}}$ Lentiviral Expression Systems (Invitrogen) according to the manufacturer's instruction. After transfection with 293FT cells for 48-72 $\mathrm{h}$, the culture medium was harvested and filtered using a $0.45 \mu \mathrm{m}$ filter (Amicon Ultra-15 100K; Millipore, Billerica, MA, USA). These recombinant lentivirus were named
LV-IL-18, LV-IFN- $\beta$ and LV-IL-18-IFN- $\beta$, respectively. For infection, BMSCs were seeded into 24-well tissue plates at $1 \times 10^{6}$ cells/well for $24 \mathrm{~h}$. Subsequently, the lentiviral supernatants were added and incubated for $24 \mathrm{~h}$. Stable clones were selected with Blasticidin S (Invitrogen). These genetically engineered BMSCs were named BMSCs-IL-18, BMSCs-IFN- $\beta$ and BMSCs-IL-18-IFN- $\beta$.

Quantitative real-time PCR ( $q R T-P C R)$. The total RNA extracted using total RNA extraction system (Qiagen, Dusseldorf, Germany) was reversely transcripted into cDNA using M-MLV reverse transcriptase (Clontech, Palo Alto, CA, USA) according to the manufacturer's instruction. qRT-PCR was performed with SYBR-Green PCR master mix (Invitrogen) on a PTC-100 DNA thermal cycler (MG Research, Waltham, MA, USA). Glyceraldehyde-3-phosphate dehydrogenase (GAPDH) was used as an internal reference for the quantification of the relative mRNA expression.

Western blot analysis. Equal amounts of proteins from different samples were loaded on $12.5 \%$ SDS-PAGE, separated and transferred to nitrocellulose membranes (Miltenyi Biotec, Auburn, CA, USA). The membranes were blocked with non-fat milk and then incubated with primary antibodies at $4^{\circ} \mathrm{C}$ overnight. Subsequently, secondary antibodies coupled with horseradish peroxidase (Bioss, Beijing, China) were added for $1 \mathrm{~h}$ at room temperature. The immunoreactive proteins were detected using an enhanced chemiluminescence reagent (GE Healthcare, Piscataway, NJ, USA). Primary antibodies, including anti-IL-18, anti-IFN- $\beta$ and anti-GAPDH were purchased from Santa Cruz Biotechnology (Santa Cruz, CA, USA).

Enzyme-linked immunosorbent assay (ELISA). The concentrations of IL-18, IFN- $\beta$, IFN- $\gamma$ and IL-2 in the cell cultured medium or tumor tissues were measured using commercial ELISA kits (R\&D Systems, Minneapolis, MN, USA) according to the manufacturer's instructions.

Cell viability assay. Cell viability was detected by 3-(4,5dimethylthiazol-2-yl)-2,5-diphenyltetrazolium bromide (MTT) assay. In brief, 9L cells were seeded into 96-well plates co-cultured with different genetically engineered BMSCs or collected cell culture medium for 24 and $48 \mathrm{~h}$. After replacement with fresh medium, $20 \mu \mathrm{l}$ of MTT $[0.5 \mathrm{mg} / \mathrm{ml}$ in phosphate-buffered saline (PBS)] was added per well and incubated for $4 \mathrm{~h}$. The medium was discarded and dimethylsulfoxide $(150 \mu \mathrm{l} / \mathrm{well})$ was added to melt the formazan for $15 \mathrm{~min}$. Absorbance was then determined at $450 \mathrm{~nm}$.

Intracranial tumor implantation and treatment. Rat 9L glioma cells were stereotactically implanted into the rat brain according to previously described methods with minor modification $(22,23)$. In brief, rats were anesthetized and placed in a stereotactic frame. The glioma cells $\left(1 \times 10^{6}\right)$ resuspended into $10 \mu 1$ of PBS were stereotactically injected into the right corpus striatum with a Hamilton syringe at a depth of $5 \mathrm{~mm}$. Three days after 9L cell implantation, the rats were treated with intratumoral inoculations of $1 \times 10^{6}$ BMSCs, BMSCs-IL-18, BMSCs-IFN- $\beta$ and BMSCs-IL-18-IFN- $\beta$ resuspended into 
A

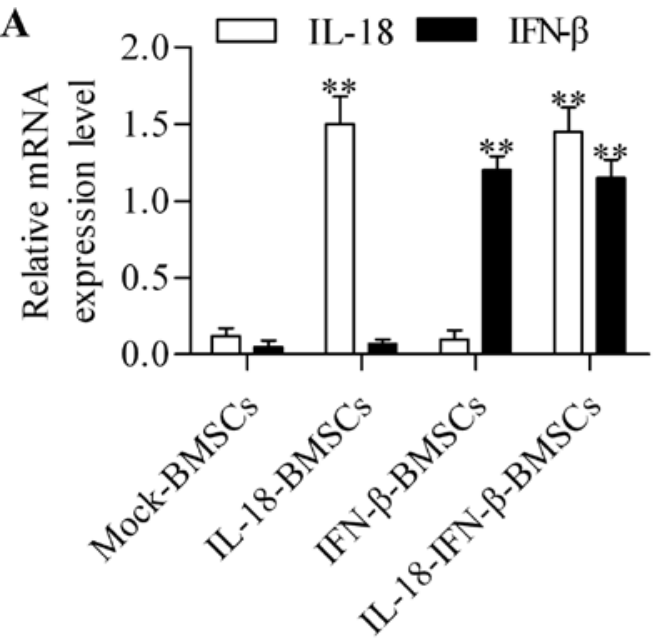

C

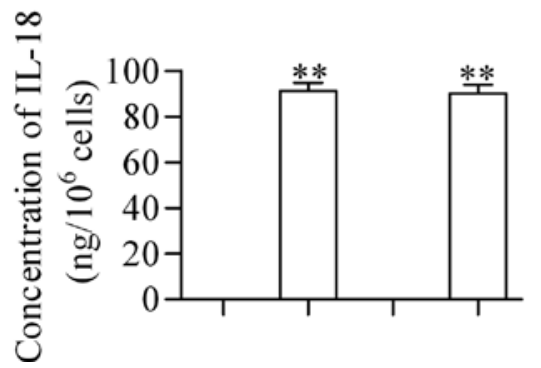

B

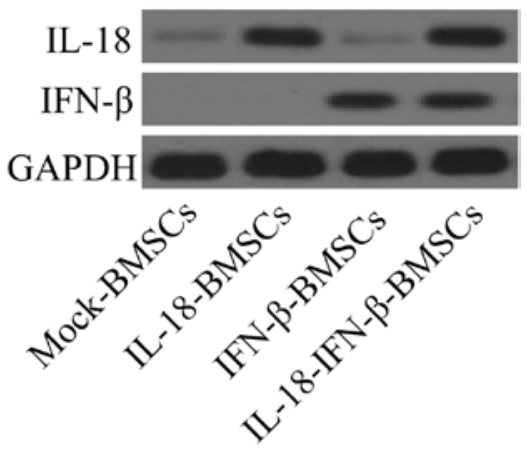

D

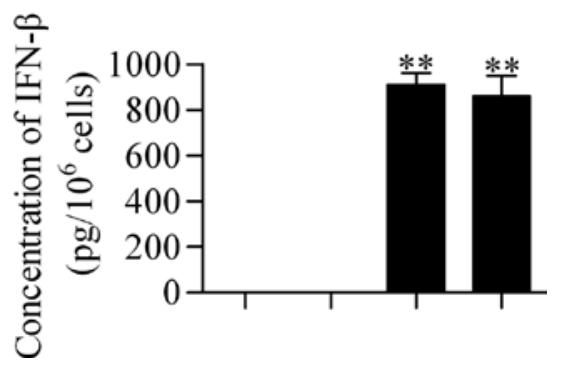

Figure 1. Detection of IL-18 and IFN- $\beta$ expression in different engineered BMSCs. Analysis of the (A) mRNA and (B) protein expression levels in IL-18-BMSCs, IFN- $\beta$-BMSCs and IL-18-IFN- $\beta$-BMSCs by qRT-PCR and western blot analysis. BMSCs infected with mock-vehicle were used as control. ${ }^{* *}$ p $<0.01$ vs. mock-BMSCs. (C) IL-18 and (D) IFN- $\beta$ expression levels in the supernatants from different cell groups were measured using ELISA kits. ${ }^{* *}$ p $<0.01$ vs. mock-BMSCs. IL-18, interleukin-18; IFN- $\beta$, interferon- $\beta$; BMSCs, bone marrow-derived mesenchymal stem cells.

$10 \mu \mathrm{l}$ of PBS. The tumor volume was monitored using a $1.5 \mathrm{~T}$ MRI system (General Electric, Syracuse, NY, USA) with 3-inch surface coil every four days for four weeks. Tumor volumes $\left(\mathrm{mm}^{2}\right)$ were calculated as follows: $(3 / 4 \pi \mathrm{x}$ length $\mathrm{x}$ width $\mathrm{x}$ height) $x 1 / 8$.

Immunohistochemical staining. After two weeks of treatment, brain tumor tissues were removed from the rats, fixed in $4 \%$ paraformaldehyde, dehydrated, frozen and serially cut into $10-\mu \mathrm{m}$ thick sections using a cryostat microtome. The sections were then incubated with anti-CD4 and anti-CD8 monoclonal antibodies (Abcam, Cambridge, UK). Immunostaining was performed using the avidin-biotin complex method with DAB color development.

Terminal deoxynucleotidyl transferase dUTP nick end labeling (TUNEL) assay. Brain tumor tissue sections were stained using the TUNEL apoptosis kit (GenMed Scientifics, Inc., Arlinghton, MA, USA) according to the manufacturer's instructions. In brief, cells were fixed with $4 \%$ paraformaldehyde and incubated with TUNEL reaction mixtures at $37^{\circ} \mathrm{C}$ for $1 \mathrm{~h}$. The stained cells were visualized and counted under a fluorescence microscope (Olympus, Tokyo, Japan). The number of apoptotic cells was counted in random fields in a blinded manner.

Statistical analysis. Data are expressed as means \pm standard deviation. One-way ANOVA was carried with SPSS software package version 11.5 (SPSS, Inc., Chicago, IL, USA) to analyze statistical differences. The survival curve was calculated with the Kaplan-Meier method. $\mathrm{p}<0.05$ was considered to indicate a statistically significant result.

\section{Results}

Stable expression of IL-18 and IFN- $\beta$ in engineered BMSCS. To detect whether IL-18 and IFN- $\beta$ were successfully introduced into BMSCs, we detected their gene expressions in these engineered BMSCs. The results of qRT-PCR and western blot analysis showed that the IL-18 and IFN- $\beta$ were expressed in IL-18-BMSCs and IFN- $\beta$-BMSCs, respectively, at the mRNA (Fig. 1A) and protein (Fig. 1B) levels. Moreover, co-expression of IL-18 and IFN- $\beta$ occurred in IL-18-IFN- $\beta$ BMSCs. We also examined the secretion levels of these proteins in conditioned media by ELISA method. The results exhibited that soluble IL-18 (Fig. 1C) and IFN- $\beta$ (Fig. 1D) were detectable in the supernatants from IL-18-BMSCs and IFN- $\beta$ BMSCs, respectively, whereas both IL-18 and IFN- $\beta$ were detected in the supernatants from IL-18-IFN- $\beta$-BMSCs. These data indicated that the engineered BMSCs were successfully established.

IL-18-IFN- $\beta$-BMSCs significantly inhibit the growth of glioma cells in vitro. To determine the effect of these engineered BMSCs on glioma cell growth, we performed the MTT assay. The results showed that IL-18-BMSCs and IFN- $\beta$-BMSCs 
A

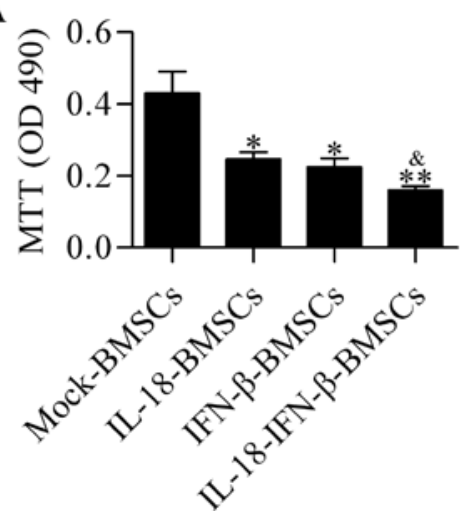

B

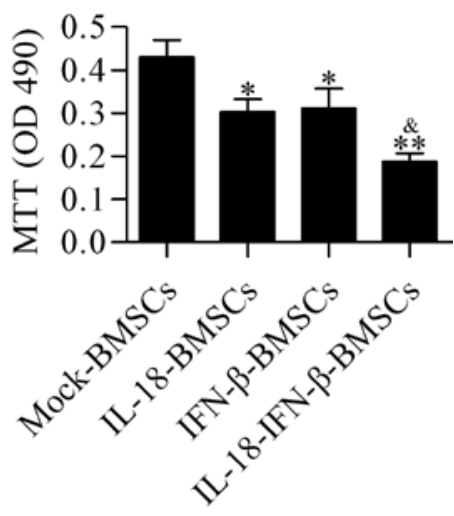

Figure 2. Detection of the cell viability. The effect of different engineered BMSCs (A) or conditioned medium from the cells (B) on glioma cell viability was determined by MTT assay. "p $<0.05,{ }^{* *} \mathrm{p}<0.01$ vs. mock-BMSCs; ${ }^{\circledR} \mathrm{p}<0.05$ vs. IL-18-BMSCs or IFN- $\beta$-BMSCs. BMSCs, bone marrow-derived mesenchymal stem cells; IL-18, interleukin-18; IFN- $\beta$, interferon- $\beta$.

A

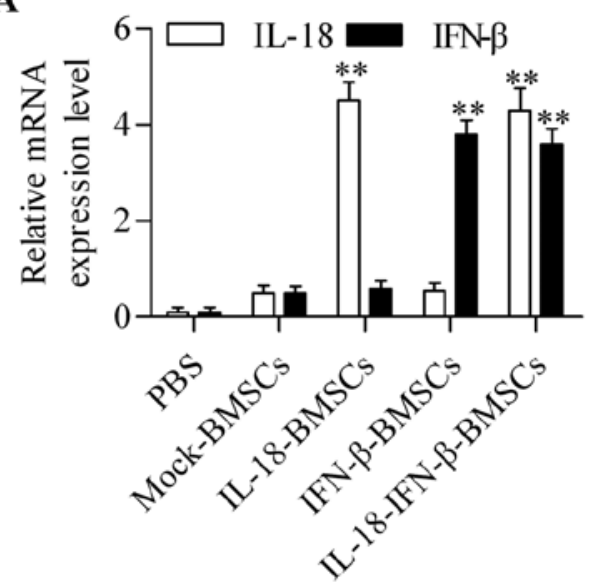

B

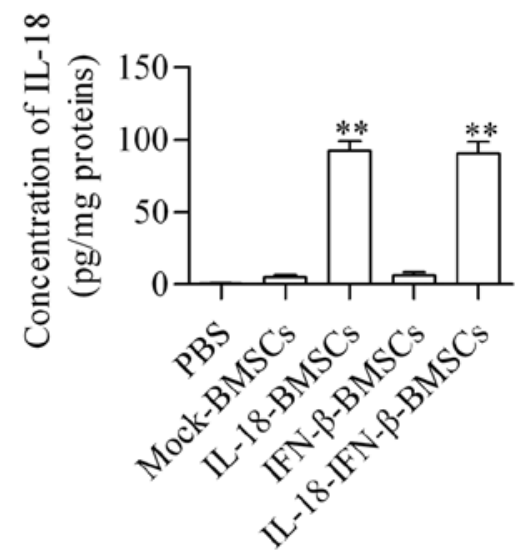

C

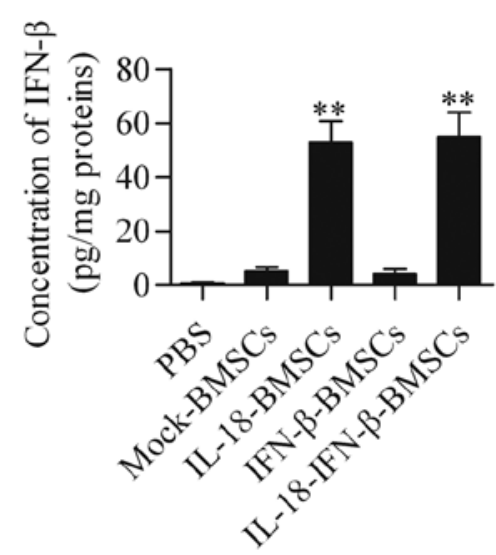

Figure 3. Expression of IL-18 and IFN- $\beta$ in intracranial glioma with treatment of different engineered BMSCs. (A) Detection of mRNA expression of IL-18 and IFN- $\beta$ in tumor mass from different engineered BMSC-treated groups by qRT-PCR. Protein expression level of (B) IL-18 and (C) IFN- $\beta$ by ELISA method. ${ }^{* *}$ p $<0.01$ vs. PBS or mock-BMSCs. IL-18, interleukin-18; IFN- $\beta$, interferon- $\beta$; BMSCs, bone marrow-derived mesenchymal stem cells.

affected the viability of glioma cells, but IL-18-IFN- $\beta$-BMSCs showed more significant inhibitory effect compared with IL-18-BMSCs or IFN- $\beta$-BMSCs (Fig. 2A). Moreover, conditioned media from IL-18-IFN- $\beta$-BMSCs displayed more potent inhibiting effect on cell viability than those from IL-18-BMSCs or IFN- $\beta$-BMSCs (Fig. 2B). These results indicated that the IL-18 and IFN- $\beta$ secreted from these engineered BMSCs were bioactive.

Treatment with IL-18-IFN- $\beta$-BMSCs significantly prolongs survival and represses intracranial glioma growth. To determine whether IL-18-IFN- $\beta$-BMSCs provided an effective therapeutic benefit against intracranial glioma growth, these engineered BMSCs were delivered into established intracranial gliomas in a rat model. The results showed that IL-18-IFN- $\beta$-BMSCs expressed both high mRNA (Fig. 3A) and secreted protein levels of IL-18 and IFN- $\beta$ (Fig. 3B and C) in the tumor mass compared with other groups. We also found that IL-18-IFN- $\beta$-BMSC treatment significantly prolonged the survival compared with IL-18-BMSC- and IFN- $\beta$-BMSCtreated groups (Fig. 4A). Furthermore, their effect on tumor volume was assessed. IL-18-IFN- $\beta$-BMSC treatment showed great inhibition of tumor growth when compared with other treatment groups (Fig. 4B).

IL-18-IFN- $\beta$-BMSCs induce potent glioma cell apoptosis. To assess apoptosis induction by different engineered BMSCs, apoptotic cells in tumors were identified by the TUNEL assay after treatment. The quantitative data indicated that IL-18-BMSC and IFN- $\beta$-BMSC treatments induced considerable cell apoptosis compared with the control group, whereas IL-18-IFN- $\beta$-BMSCs induced tumor cell apoptosis more potently than the other groups (Fig. 5A).

IL-18-IFN- $\beta$-BMSCs induce strong production of IL-2 and $I F N-\gamma$. To further verify that IL-18-IFN- $\beta$-BMSCs potentiated strong antitumor effect, we detected the expression of IL-2 and IFN- $\gamma$, which were closely related producing antitumor effect (24) in tumor tissues with ELISA method. The tumor tissues from IL-18-BMSC- or IFN- $\beta$-BMSC-treated rats displayed higher levels of IL-2 and IFN- $\gamma$ than those from the control group. Significant differences were also 

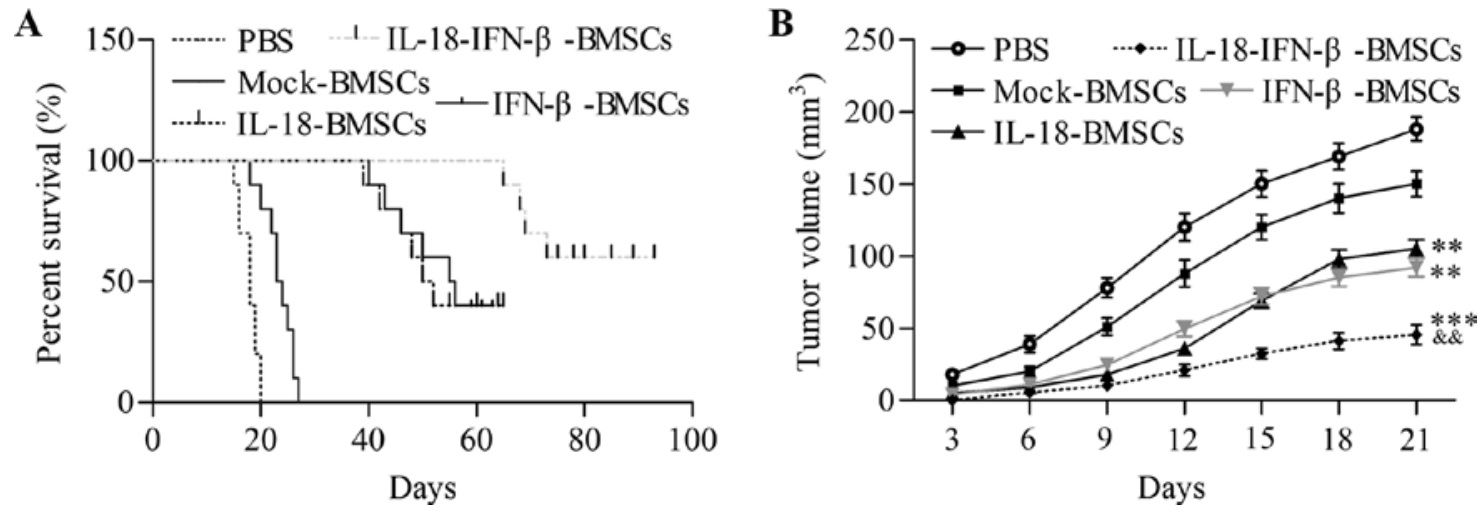

Figure 4. Treatment effect of IL-18-IFN- $\beta$-BMSCs on intracranial glioma. (A) Kaplan-Meier survival curve of intracranial glioma-bearing rat treated with different engineered BMSCs. N=10/group. (B) Tumor volume of the groups. ${ }^{* *} \mathrm{p}<0.01,{ }^{* * *} \mathrm{p}<0.001$ vs. PBS or mock-BMSCs; ${ }^{* \&} \mathrm{p}<0.01$ vs. IL-18-BMSCs or IFN- $\beta$-BMSCs. IL-18, interleukin-18; IFN- $\beta$, interferon- $\beta$; BMSCs, bone marrow-derived mesenchymal stem cells.

A

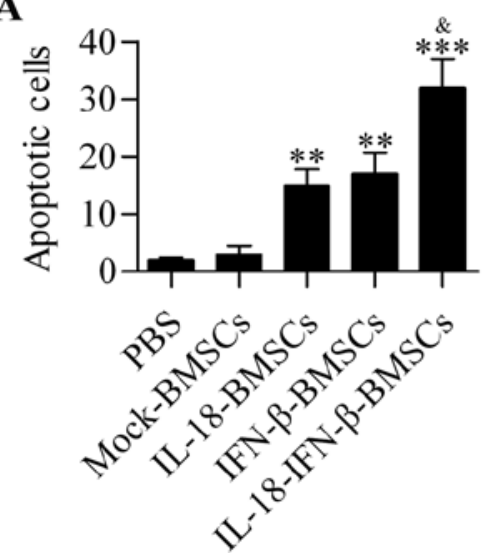

B

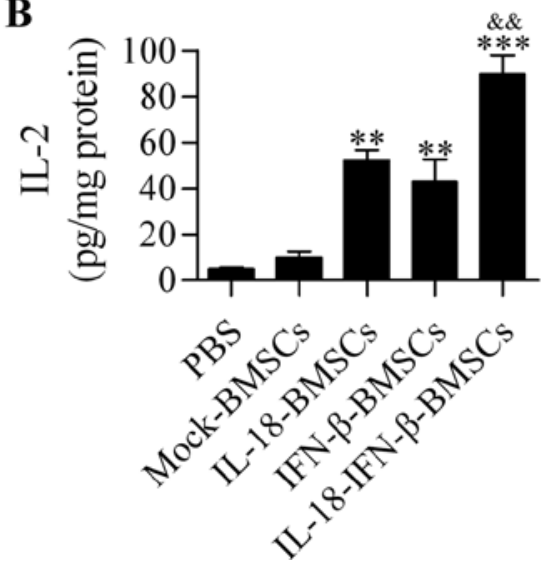

C

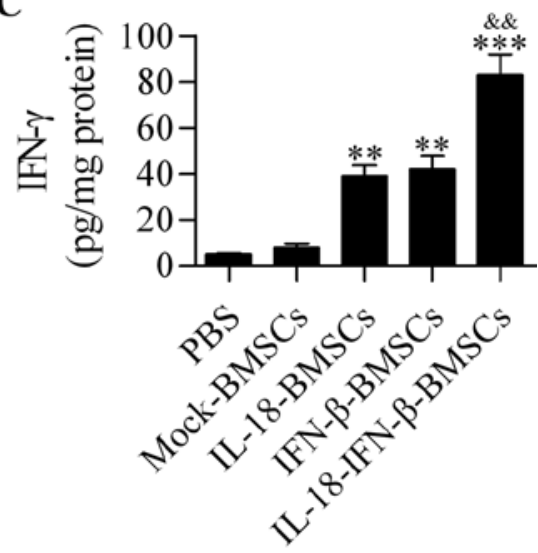

Figure 5. Treatment effect of IL-18-IFN- $\beta$-BMSCs on cell apoptosis induction and antitumor cytokine expression. (A) Cell apoptosis in tumors from glioma-bearing rats treated with different engineered BMSCs as detected by TUNEL assay. The mean amount of apoptotic cells was quantified. (B) IL-2 and (C) IFN- $\gamma$ expression levels in tumor tissues from different groups were detected by ELISA method. ${ }^{* *}$ p $<0.01,{ }^{* * *}$ p $<0.001$ vs. PBS or mock-BMSCs; ${ }^{\&} \mathrm{p}<0.05,{ }^{\&} \mathrm{p}<0.01$ vs. IL-18-BMSCs or IFN- $\beta$-BMSCs. IL-18, interleukin-18; IIFN- $\beta$, interferon- $\beta$; BMSCs, bone marrow-derived mesenchymal stem cells.

observed between rats treated with IL-18-IFN- $\beta$-BMSCs and IL-18-BMSCs or IFN- $\beta$-BMSCs (Fig. 5B and C).

IL-18-IFN- $\beta$-BMSCs induces enhanced $C D 4^{+}$and $C D 8^{+}$ T-cell infiltration in intracranial glioma. Tumor-infiltrating $\mathrm{T}$ cells in glioma patient are beneficial for prolonging survival $(25,26)$. Negligible $\mathrm{CD}^{+}$and $\mathrm{CD}^{+}{ }^{+}$T-cell infiltrations were observed in mock-BMSC-treated groups. A certain degree of tumor-infiltrating $\mathrm{CD}^{+}$and $\mathrm{CD}^{+} \mathrm{T}$ cells was also found in animals receiving IL-18-BMSCs or IFN- $\beta$-BMSCs treatment. IL-18-IFN- $\beta$-BMSC treatments induced more robust $\mathrm{CD}^{+}$and $\mathrm{CD}^{+} \mathrm{T}$-cell infiltration in intracranial glioma than the other groups (Fig. 6A-C).

\section{Discussion}

The use of BMSCs as a gene transfer vehicle in the treatment of BMSCs has been extensively investigated (27). BMSCs expressing herpes simplex virus-thymidine kinase suppress glioma tumor growth in a mouse model (28). BMSCs expressing soluble tumor necrosis factor-related apoptosis-inducing ligand
(TRAIL) induce substantial tumor cell apoptosis in intracranial glioma in a mouse model and significantly improve the survival rate (29). Moreover, TRAIL-engineered BMSCs exhibit cytotoxic effects on glioma cells in vitro (30). In the present study, we demonstrated that BMSCs co-expressing IL-18 and IFN- $\beta$ displayed a more potent antitumor effect than BMSCs solely expressing IL-18 or IFN- $\beta$. This result implies a significant synergistic effect of IL-18 and IFN- $\beta$ in glioma treatment. The present study, not only confirmed that BMSCs served as a powerful delivery vehicle for glioma treatment, but also provided novel insight for the improvement of glioma gene therapy using BMSCs.

Overexpression of IL-18 induces cell apoptosis of human tongue squamous cell carcinoma cells (31) by regulating glycogen synthase kinase-3 $\beta$ signaling (32). Adenovirusmediated expression of IL-18 induces significant cell apoptosis and inhibits angiogenesis against melanoma in mice (33). In addition, IFN- $\beta$ inhibits the proliferation and angiogenesis of malignant glioma cells (34) and displays potent antiproliferative activity against melanoma and glioma cells $(18,35,36)$. In the present study, we found that IL-18-BMSCs or IFN- $\beta$-BMSCs 


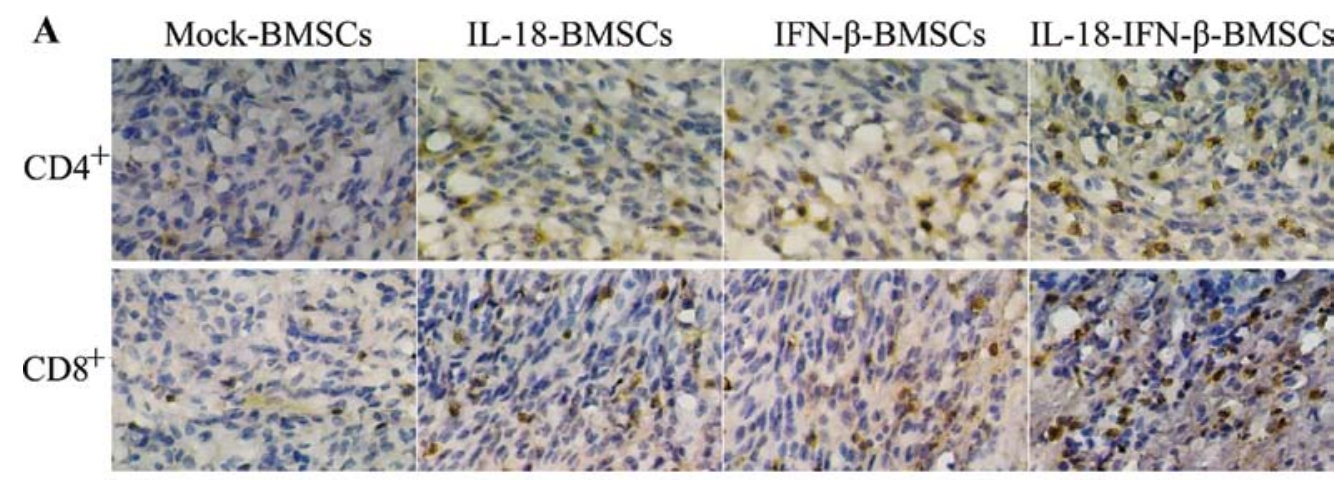

B

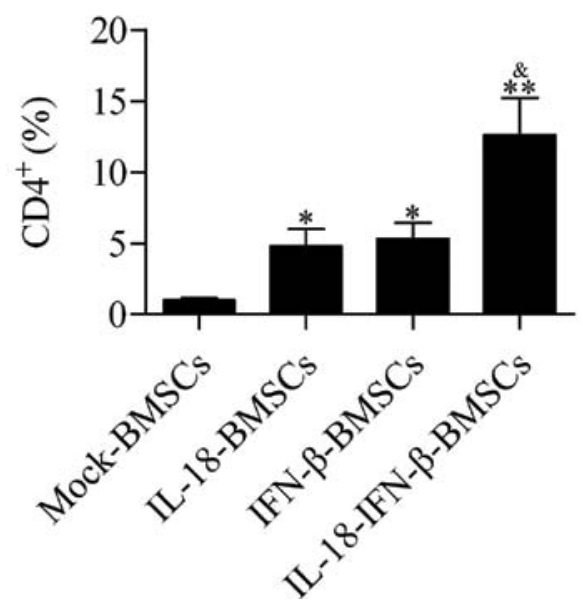

C

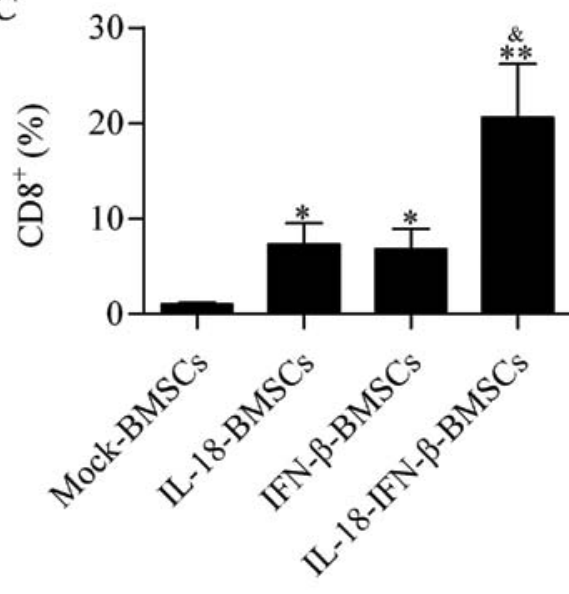

Figure 6. Treatment effect of IL-18-IFN- $\beta$-BMSCs on T-cell infiltration in intracranial glioma. (A) $\mathrm{CD}^{+}$and $\mathrm{CD} 8^{+} \mathrm{T}$-cell infiltrations in tumor tissues were detected by immunohistochemistry with corresponding antibodies. Quantitative analysis of intratumoral (B) $\mathrm{CD} 4^{+}$and $(\mathrm{C}) \mathrm{CD} 8^{+} \mathrm{T}$ cells. Data were calculated as percent of positive staining cells/total cells in tumor area. ${ }^{*} \mathrm{p}<0.05,{ }^{* *} \mathrm{p}<0.01$ vs. mock-BMSCs; ${ }^{\circledR} \mathrm{p}<0.05$ vs. IL-18-BMSCs or IFN- $\beta$-BMSCs. IL-18, interleukin-18; IFN- $\beta$, interferon- $\beta$; BMSCs, bone marrow-derived mesenchymal stem cells.

successfully expressed IL-18 or IFN- $\beta$ and significantly inhibited the cell growth of glioma cells. Furthermore, the condition medium from these cultured cells also inhibited cell growth of glioma cells, thus implying that the secreted IL-18 or IFN- $\beta$ from engineered BMSCs was bioactive. Surprisingly, IL-18-IFN- $\beta$-BMSCs co-expressing IL-18 or IFN- $\beta$ exhibited a more significant growth inhibition on glioma cells than those solely expressing BMSCs. These data suggest that combined IL-18 and IFN- $\beta$ treatment may have potent antitumor effect on glioma. Similarly, co-expression of IL-18 and Fas enhanced the apoptosis of glioma cells (37). Thereby, the combined utilization of antitumor drugs or biological agents may produce more satisfactory antitumor effect.

The sole use of IL-18 or IFN- $\beta$ as immunostimulatory cytokine in the treatment of various types of cancers, including gliomas, has been widely studied reporting that IL-18 is a powerful adjuvant for immunotherapy and vaccine therapy and is safe for clinical use $(38,39)$. Intracerebral injection of recombinant IL-18 inhibits the gliomas located in the mouse brain (40), whereas intramuscular injection promotes antigenspecific immune responses mediated by $\mathrm{CD} 4^{+} / \mathrm{CD} 8^{+} \mathrm{T}$ cells against brain tumors (41). The glioma cells co-expression of IL-18 and Fas shows reduced tumorigenicity (37). Dendritic cells loaded with tumor lysates and IL-18 elicit CD8 ${ }^{+}$cytotoxic T cell response against glioma in patients (42). Similarly, dendritic cells that are genetically engineered to express IL-18 combined with the administration of IL-12 significantly induce tumor-specific $\mathrm{CD} 4^{+} / \mathrm{CD} 8^{+} \mathrm{T}$ cells and natural killer cells against glioma cells (43). Treatment of adeno-associated virus encoding human IFN- $\beta$ completely prevents tumor growth and improves the survival of glioma mouse model $(44,45)$. Co-administration of IFN- $\beta$ and dendritic cells accelerates cell apoptosis and induces specific T-cell responses against glioma cell (16). The intratumoral injection of liposomes containing IFN- $\beta$ reduces tumor growth and induces massive $\mathrm{T}$ cell infiltration within the residual tumor (19). To date, the gene transfer of IL-18 or IFN- $\beta$ using BMSCs has rarely been investigated. In our previous study, we demonstrated that adenoviral-mediated IL-18 expression in BMSCs effectively suppressed the growth of glioma in rats (21), thereby providing a promising new treatment option for malignant glioma. In the present study, we investigated the treatment effect of the BMSCs co-expression of IL-18 or IFN- $\beta$ on glioma. The data demonstrated that this co-expression displayed more significant inhibition effect on glioma, including prolonged survival and reduced tumor growth in intracranial glioma in rats, compared with BMSCs solely expressing IL-18 or IFN- $\beta$. The underlying mechanism may be that IL-18 and IFN- $\beta$ synergistically promoted antitumor immunity, in which antitumor cytokines IL-2 and IFN- $\gamma$ production and $\mathrm{CD}^{+}$and $\mathrm{CD} 8^{+}$ T-cell infiltration in intracranial glioma were significantly promoted.

The present study is the first to investigate the effect of BMSCs that were genetically engineered with IL-18 and 
IFN- $\beta$ for the treatment of experimental glioma in a rat model. We found that BMSCs co-expressing IL-18 and IFN- $\beta$ significantly induced cell apoptosis, prolonged survival and reduced tumor growth of intracranial glioma. Their co-expression elicits more potent antitumor immune response than BMSCs solely expressing IL-18 or IFN- $\beta$. Our results suggested that delivery of IL-18 and IFN- $\beta$ by BMSCs may be an excellent and promising approach for the development of an effective treatment protocol for glioma therapy.

\section{Acknowledgements}

The present study was supported by the Natural Science Foundation of Shaanxi Province of China (no. 2014JM2-8179).

\section{References}

1. Mao XG, Zhang X and Zhen HN: Progress on potential strategies to target brain tumor stem cells. Cell Mol Neurobiol 29: 141-155, 2009.

2. Maher EA, Furnari FB, Bachoo RM, Rowitch DH, Louis DN, Cavenee WK and DePinho RA: Malignant glioma: Genetics and biology of a grave matter. Genes Dev 15: 1311-1333, 2001.

3. Sanai $\mathrm{N}$ and Berger MS: Glioma extent of resection and its impact on patient outcome. Neurosurgery 62: 753-764, discussion 264-266, 2008.

4. Bexell D, Gunnarsson S, Tormin A, Darabi A, Gisselsson D, Roybon L, Scheding S and Bengzon J: Bone marrow multipotent mesenchymal stroma cells act as pericyte-like migratory vehicles in experimental gliomas. Mol Ther 17: 183-190, 2009.

5. Gunnarsson S, Bexell D, Svensson A, Siesjö P, Darabi A and Bengzon J: Intratumoral IL-7 delivery by mesenchymal stromal cells potentiates IFNgamma-transduced tumor cell immunotherapy of experimental glioma. J Neuroimmunol 218: 140-144, 2010.

6. Matuskova M, Hlubinova K, Pastorakova A, Hunakova L, Altanerova V, Altaner C and Kucerova L: HSV-tk expressing mesenchymal stem cells exert bystander effect on human glioblastoma cells. Cancer Lett 290: 58-67, 2010.

7. Suryadevara CM, Verla T, Sanchez-Perez L, Reap EA, Choi BD, Fecci PE and Sampson JH: Immunotherapy for malignant glioma. Surg Neurol Int 6 (Suppl 1): S68-S77, 2015.

8. Okamura H, Tsutsi H, Komatsu T, Yutsudo M, Hakura A, Tanimoto T, Torigoe K, Okura T, Nukada Y, Hattori K, et al: Cloning of a new cytokine that induces IFN-gamma production by T cells. Nature 378: 88-91, 1995.

9. Hwang KS, Cho WK, Yoo J, Seong YR, Kim BK, Kim S and Im DS: Adenovirus-mediated interleukin-18 mutant in vivo gene transfer inhibits tumor growth through the induction of T cell immunity and activation of natural killer cell cytotoxicity. Cancer Gene Ther 11: 397-407, 2004.

10. Ossendorp F, Mengedé E, Camps M, Filius R and Melief CJ: Specific $T$ helper cell requirement for optimal induction of cytotoxic T lymphocytes against major histocompatibility complex class II negative tumors. J Exp Med 187: 693-702, 1998.

11. Kohyama M, Saijyo K, Hayasida M, Yasugi T, Kurimoto M and Ohno T: Direct activation of human $\mathrm{CD} 8^{+}$cytotoxic T lymphocytes by interleukin-18. Jpn J Cancer Res 89: 1041-1046, 1998.

12. Xia D, Li F and Xiang J: Engineered fusion hybrid vaccine of IL-18 gene-modified tumor cells and dendritic cells induces enhanced antitumor immunity. Cancer Biother Radiopharm 19: 322-330, 2004.

13. Glick RP, Lichtor T, Mogharbel A, Taylor CA and Cohen EP: Intracerebral versus subcutaneous immunization with allogeneic fibroblasts genetically engineered to secrete interleukin-2 in the treatment of central nervous system glioma and melanoma. Neurosurgery 41: 898-906; discussion 906-907, 1997.

14. Sobol RE, Fakhrai H, Shawler D, Gjerset R, Dorigo O, Carson C, Khaleghi T, Koziol J, Shiftan TA and Royston I: Interleukin-2 gene therapy in a patient with glioblastoma. Gene Ther 2: 164-167, 1995.

15. Hertzog PJ, Hwang SY and Kola I: Role of interferons in the regulation of cell proliferation, differentiation, and development. Mol Reprod Dev 39: 226-232, 1994
16. Nakahara N, Pollack IF, Storkus WJ, Wakabayashi T, Yoshida J and Okada $\mathrm{H}$ : Effective induction of antiglioma cytotoxic $\mathrm{T}$ cells by coadministration of interferon-beta gene vector and dendritic cells. Cancer Gene Ther 10: 549-558, 2003.

17. Williams RF, Myers AL, Sims TL, Ng CY, Nathwani AC and Davidoff AM: Targeting multiple angiogenic pathways for the treatment of neuroblastoma. J Pediatr Surg 45: 1103-1109, 2010.

18. Kageshita T, Mizuno M, Ono T, Matsumoto K, Saida T and Yoshida J: Growth inhibition of human malignant melanoma transfected with the human interferon-beta gene by means of cationic liposomes. Melanoma Res 11: 337-342, 2001.

19. Natsume A, Mizuno M, Ryuke Y and Yoshida J: Antitumor effect and cellular immunity activation by murine interferon-beta gene transfer against intracerebral glioma in mouse. Gene Ther 6: 1626-1633, 1999.

20. Natsume A, Tsujimura K, Mizuno M, Takahashi T and Yoshida J: IFN-beta gene therapy induces systemic antitumor immunity against malignant glioma. J Neurooncol 47: 117-124, 2000.

21. Xu G, Jiang XD, Xu Y, Zhang J, Huang FH, Chen ZZ, Zhou DX, Shang JH, Zou YX and Cai YQ: Adenoviral-mediated interleukin-18 expression in mesenchymal stem cells effectively suppresses the growth of glioma in rats. Cell Biol Int 33: 466-474, 2009.

22. Olson JJ, Friedman R, Orr K, Delaney T and Oldfield EH: Enhancement of the efficacy of $\mathrm{x}$-irradiation by pentobarbital in a rodent brain-tumor model. J Neurosurg 72: 745-748, 1990.

23. Farrell CL, Stewart PA and Del Maestro RF: A new glioma model in rat: The C6 spheroid implantation technique permeability and vascular characterization. J Neurooncol 4: 403-415, 1987.

24. Chen W, Wang J, Shao C, Liu S, Yu Y, Wang Q and Cao X: Efficient induction of antitumor $\mathrm{T}$ cell immunity by exosomes derived from heat-shocked lymphoma cells. Eur J Immunol 36: 1598-1607, 2006.

25. Lohr J, Ratliff T, Huppertz A, Ge Y, Dictus C, Ahmadi R, Grau S, Hiraoka N, Eckstein V, Ecker RC, et al: Effector T-cell infiltration positively impacts survival of glioblastoma patients and is impaired by tumor-derived TGF- $\beta$. Clin Cancer Res 17: 4296-4308, 2011.

26. Kraman M, Bambrough PJ, Arnold JN, Roberts EW, Magiera L, Jones JO, Gopinathan A, Tuveson DA and Fearon DT: Suppression of antitumor immunity by stromal cells expressing fibroblast activation protein-alpha. Science 330: 827-830, 2010.

27. Nakamizo A, Marini F, Amano T, Khan A, Studeny M, Gumin J, Chen J, Hentschel S, Vecil G, Dembinski J, et al: Human bone marrow-derived mesenchymal stem cells in the treatment of gliomas. Cancer Res 65: 3307-3318, 2005.

28. Uchibori R, Okada T, Ito T, Urabe M, Mizukami H, Kume A and Ozawa K: Retroviral vector-producing mesenchymal stem cells for targeted suicide cancer gene therapy. J Gene Med 11: 373-381, 2009.

29. Menon LG, Kelly K, Yang HW, Kim SK, Black PM and Carroll RS: Human bone marrow-derived mesenchymal stromal cells expressing S-TRAIL as a cellular delivery vehicle for human glioma therapy. Stem Cells 27: 2320-2330, 2009.

30. Tang XJ, Lu JT, Tu HJ, Huang KM, Fu R, Cao G, Huang M, Cheng LH, Dai LJ and Zhang L: TRAIL-engineered bone marrow-derived mesenchymal stem cells: TRAIL expression and cytotoxic effects on C6 glioma cells. Anticancer Res 34: 729-734, 2014.

31. Liu W, Han B, Sun B, Gao Y, Huang Y and Hu M: Overexpression of interleukin-18 induces growth inhibition, apoptosis and gene expression changes in a human tongue squamous cell carcinoma cell line. J Int Med Res 40: 537-544, 2012.

32. Liu W, Hu M, Wang Y, Sun B, Guo Y, Xu Z, Li J and Han B: Overexpression of interleukin-18 protein reduces viability and induces apoptosis of tongue squamous cell carcinoma cells by activation of glycogen synthase kinase- $3 \beta$ signaling. Oncol Rep 33: 1049-1056, 2015.

33. Zheng JN, Pei DS, Mao LJ, Liu XY, Sun FH, Zhang BF, Liu YQ, Liu JJ, Li W and Han D: Oncolytic adenovirus expressing interleukin-18 induces significant antitumor effects against melanoma in mice through inhibition of angiogenesis. Cancer Gene Ther 17: 28-36, 2010.

34. Takano S, Ishikawa E, Matsuda M, Yamamoto $\mathrm{T}$ and Matsumura A: Interferon- $\beta$ inhibits glioma angiogenesis through downregulation of vascular endothelial growth factor and upregulation of interferon inducible protein 10. Int J Oncol 45: 1837-1846, 2014. 
35. Yoshida J, Mizuno M and Yagi K: Cytotoxicity of human beta-interferon produced in human glioma cells transfected with its gene by means of liposomes. Biochem Int 28: 1055-1061, 1992 .

36. Guo Y, Wang G, Gao WW, Cheng SW, Wang R, Ju SM, Cao HL and Tian HL: Induction of apoptosis in glioma cells and upregulation of Fas expression using the human interferon- $\beta$ gene. Asian Pac J Cancer Prev 13: 2837-2840, 2012.

37. Zhang Y, Wang C, Zhang Y and Sun M: C6 glioma cells retrovirally engineered to express IL-18 and Fas exert FasL-dependent cytotoxicity against glioma formation. Biochem Biophys Res Commun 325: 1240-1245, 2004.

38. Marshall DJ, Rudnick KA, McCarthy SG, Mateo LR, Harris MC, McCauley C and Snyder LA: Interleukin-18 enhances Th1 immunity and tumor protection of a DNA vaccine. Vaccine 24 : 244-253, 2006.

39. Robertson MJ, Mier JW, Logan T, Atkins M, Koon H, Koch KM, Kathman S, Pandite LN, Oei C, Kirby LC, et al: Clinical and biological effects of recombinant human interleukin-18 administered by intravenous infusion to patients with advanced cancer. Clin Cancer Res 12: 4265-4273, 2006.

40. Kikuchi T, Akasaki Y, Joki T, Abe T, Kurimoto M and Ohno T: Antitumor activity of interleukin-18 on mouse glioma cells. J Immunother 23: 184-189, 2000.
41. Yamanaka R and Xanthopoulos KG: Induction of antigenspecific immune responses against malignant brain tumors by intramuscular injection of sindbis DNA encoding gp100 and IL-18. DNA Cell Biol 24: 317-324, 2005.

42. Yamanaka R, Honma J, Tsuchiya N, Yajima N, Kobayashi T and Tanaka R: Tumor lysate and IL-18 loaded dendritic cells elicits Th1 response, tumor-specific $\mathrm{CD} 8^{+}$cytotoxic $\mathrm{T}$ cells in patients with malignant glioma. J Neurooncol 72: 107-113, 2005.

43. Yamanaka R, Tsuchiya N, Yajima N, Honma J, Hasegawa H, Tanaka R, Ramsey J, Blaese RM and Xanthopoulos KG: Induction of an antitumor immunological response by an intratumoral injection of dendritic cells pulsed with genetically engineered Semliki Forest virus to produce interleukin-18 combined with the systemic administration of interleukin-12. J Neurosurg 99: 746-753, 2003

44. Meijer DH, Maguire CA, LeRoy SG and Sena-Esteves M: Controlling brain tumor growth by intraventricular administration of an AAV vector encoding IFN-beta. Cancer Gene Ther 16: 664-671, 2009

45. Streck CJ, Dickson PV, Ng CY, Zhou J, Hall MM, Gray JT, Nathwani AC and Davidoff AM: Antitumor efficacy of AAV-mediated systemic delivery of interferon-beta. Cancer Gene Ther 13: 99-106, 2006. 